More rapid progress would be welcome, since developments elsewhere in the world are beginning to make British efforts look leaden footed. In France, the Aerotrain test vehicle, propelled by a temporary rocket attachment, reached a speed of 188 m.p.h. along its short test track recently. In Britain, the corresponding project is still at the model building stage, and seems to have raised no enthusiasm in British Rail. On the naval side, there is interest in vehicles in which the sidewalls are immersed so that the air cushion is trapped; these are particularly suitable for comparatively low speeds. Military strategists on both sides of the Atlantic should by now have firm ideas about how useful hovercraft are likely to be in a military role, since both the United Kingdom and the United States have used them in operations in the Far East.

At the moment, too many hovercraft projects in Britain seem to be hanging fire, which makes it easy for American companies to coax British engineers to emigrate. NRDC, whose source of funds is now the Ministry of Technology, has spent more on hovercraft than on any other project, but the total since 1958 is only $£ 2.5 \mathrm{~m}$. This is derisory in comparison with the share in the Anglo-French variable geometry projectat least $£ 100 \mathrm{~m}-$ which Britain has cheerfully taken on. Perhaps Mr. Benn's enthusiasm will divert similar largesse towards the NPL when it starts work; until then the British effort, like the hovercraft themselves, appears to have no visible means of support.

\section{X-Ray Camera}

THE resolution of $\mathrm{X}$-ray diffraction patterns is increased if the X-ray beam is well collimated. While good resolution is always important in crystallography, it is particularly important when partially ordered materials are being studied, since even in the ideal case the patterns are likely to be diffuse. If very fine apertures are used to provide a collimated beam, the exposure time is greatly increased, and may run into weeks. The Franks camera, commonly used for work on partially ordered materials at low Bragg angles, focuses and collimates the beam by reflexion from two mirrors at grazing incidence, but suffers from the disadvantage of a very low angular aperture. Reflexion at grazing incidence has now been used by Dr. A. Elliott of the Department of Biophysics at King's College, London, for a new camera which he has developed for work at higher Bragg angles. (For spacings $<50 \AA$.)

In Dr. Elliott's camera the X-ray beam is focused as it passes along a capillary tube the internal profile of which is barrel-shaped. The tube, about $3 \mathrm{~mm}$ wide at its widest point and several $\mathrm{cm}$ long, is coated internally with gold, which has the highest known reflexion for $\mathrm{X}$-rays. Even so, for copper $\mathrm{K} \alpha$ radiation the glancing angle is only about $\frac{1}{2}^{\circ}$; a similar design built in the United States by Henke and DuMond (J.Appl. Phys., 26,903 ; 1955) was not suitable for X-rays of wavelength shorter than aluminium $K$ radiation, for which the glancing angle is three times greater. Dr. Elliott has succeeded in producing a mirror small enough for use with copper $\mathrm{K}_{\alpha}$ radiation by a casting technique with epoxy resins.

The camera is suitable for high angle work; the difficulty at low Bragg angles is that scattering of the main beam interferes with the pattern. At high angles, however, the camera gives about a ten-fold increase in intensity and very good definition, as well as acting as a monochromator. The high angle diffraction pattern of muscle has been studied in greater detail than before, and liquid crystals have also been studied (Parry and Elliott, Nature, 206, 616; 1965). The design can also be used in powder cameras, and is being used in X-ray fluorescent analysis by $\mathrm{Mr}$. R. W. Fearnhead at the London Hospital Medical College. The method has not yet been applied at King's for the study of active muscle, despite the impression given by a previous item in Nature (212, 969; 1966), but it is hoped that this will be done in the future. The advantages of the camera should become more generally available soon, when it is marketed commercially.

\section{Geophysics in India}

THE annual meeting of the Indian Geophysical Union was held on January 5 this year. In his presidential address Dr. M. S. Krishnan spoke about the structure of south-east Asia with particular reference to the Mesozoic and Tertiary island arcs. The chief guest at the meeting was Dr. Atma Ram, Director-General of the Indian Council of Scientific and Industrial Research, who emphasized the importance of geophysics in exploring the natural resources of the country at a time when India desperately needed natural resources. The Krishnan medal for the year 1966 was awarded to Dr. H. M. Iyer for his outstanding contribution in the field of seismology. The medal for 1965 was presented to Dr. D. Lal at the meeting. Honorary Fellowships of the Indian Geophysical Union were conferred on the following: Dr. K. R. Ramanathan, Dr. Maurice Ewing, Dr. Tuzo Wilson, Professor V. V. Beloussov, Sir Edward Bullard, Dr. T. Nagata and Madam Kosminskaya.

\section{East African Academy}

MaN in his East African environment was the principal theme of the fourth symposium of the East African Academy, which was held in Kampala in September. In the opening address the vice-president of Uganda, Mr. J. K. Babüha, challenged the academy not to "look at East Africa and its problems from the dizzy heights of [an] academic ivory tower', but to use its knowledge to help the less fortunate to a better way of life. In five plenary sessions, evolutionary and cultural aspects of life in East Africa were discussed. The role of nationalism, urbanism and tribalism in contemporary Africa was examined, and in another session the changing pattern of disease and the effects of environmental change on this were traced. In a special plenary session the president of the academy, Dr. W. K. Chagula, discussed the role of the educated East Africans in developing their countries, and Dr. Chidzero of the United Nations, from Nairobi, in the distinguished lecture-a new feature of this symposium--examined the reasons for international aid programmes and the need to expand them. These programmes must be synchronized with local efforts if living standards are to be much improved. There is a danger, he warned, of using economic assistance either to provide jobs for international civil servants or as a camouflage to sabotage the political independence of recipient countries. 